\title{
"Com seu vento, ele pôs Yam em sua rede" - proposta (de H. R. [Chaim] Cohen) de correção do texto de Jó 26,13a na BHS
}

\author{
"By his wind, he put Yam into his net" - (R. H. [Chaim] Cohen) correction proposal \\ of the BHS text of Job 26:13
}

Osvaldo Luiz Ribeiro*

\begin{abstract}
Resumo
Formula-se como proposta de crítica textual, a sugestão de correção do texto de Jó 26,13a da Biblia Hebraica Stuttgartensia, constante da dissertação por Harold R. (Chaim) Cohen, de 1975, publicada em 1978, com o título de Biblical Hapax Legomena in the Light of Akkadian and Ugarit. Cohen apresenta duas declarações: a) recupera a recomendação de Tur-Sinai (1941), de que o vocábulo שפ de Jó 26,13a deva ser traduzido a partir do cognato acádico, "saparru", interpretando-se-lhe como "rede", de modo que se trataria, então, de um caso de hapax legomenon. Além disso, 2) Cohen afirma que houve erro de copista na transmissão do verso hebraico - dois vocábulos originais independentes - שם e - teriam sido equivocadamente aglutinados pelo escriba e transformados no agora constante do texto padrão da BHS, שִִּ . As sugestões de Cohen recuperam a condição de paralelismo sinonímicos dos quatro estíquios de Jó 26,12-13, uma vez que, Yam, aparecendo no se e então corrigido v. 13a, comporia paralelo com os demais dragões mencionados nos v. 12a, 12b e 13b. Jó 26,13a deveria, então, ser lido da seguinte forma: "com seu vento, ele pôs Yam em sua rede". Não se identificou qualquer versão ou comentário que houvesse acatado a sugestão de Cohen.
\end{abstract}

Palavras-chave: Jó 26,12-13; hapax legomena; Harold R. (Chaim) Cohen; cosmogonia; crítica textual

\begin{abstract}
Is formulated as a proposed textual criticism the suggestion of correction of the text of Job 26.13 of the Hebrew Bible Stuttgartensia, constant of dissertation by Harold R. (Chaim ) Cohen , 1975, published in 1978, with the title of Biblical Hapax in the Light of Akkadian and Ugaritic . Cohen presents two statements: 1) retrieves the recommendation of Tur-Sinai ( 1941), that the word שn Job 26.13 should be translated from Akkadian cognate, "saparru", playing to him as "network", so that , then, would treat a case of hapax legomena. Also, 2) Cohen says there were copyist error in the transmission of the Hebrew verse - two independent original vocabulary - שם and - have been mistakenly clumped by the scribe and processed in the now constant standard text of BHS, The Cohen's suggestions recover the condition of the four parallel synonymic verses in Job 26.12-13, since Yam, appearing in if and then corrected v . 13a, compose parallel with the other dragons mentioned in v. 12a, 12b and 13b. Job 26.13 should then be read as follows: " with his wind, he put Yam on your network". Not identified any version or comment that had heeded the suggestion of Cohen.
\end{abstract}

Keywords: Job 26.12-13; hapax legomena; Harold R. (Chaim) Cohen; cosmogony; textual criticism.

Artigo recebido em 07 out. 2014 e aprovado em 26 de junho de 2015

* Doutor em Teologia. Professor e Coordenador do Mestrado em Ciências das Religiões da Faculdade Unida de Vitória. País de origem: Brasil. E-mail: osvaldo@faculdadeunida.com.br. 


\section{Introdução}

Causa direta do presente artigo é um livro de Harold R. Cohen, que, "in its original form, was presented as dissertation to the Faculty of Philosophy of Columbia University in 1975" (COHEN, 1978, p. xv). Na forma em que se encontra, ainda datilografada, foi publicada na Dissertation Series da Society of Biblical Literature - Harold R. (Chaim) Cohen, Biblical Hapax Legomena in the Light of Akkadian and Ugarit, Missoula: Scholar Press, 1978.

Do livro de Cohen, para o presente artigo, constitui interesse a discussão de Cohen sobre Jó 26,13. Cohen faz duas afirmações que, a rigor, já deveriam ter redundado na alteração não apenas do texto hebraico da Biblia Hebraica Stuttgartensia (BHS), mas, por extensão, das traduções da Bíblia Hebraica e das Escrituras cristã e judaica em circulação.

De um lado, considerando-a um caso de hapax legomenon, Cohen sugere que se perdeu o sentido originalmente acádico da palavra hebraica שפרה. De outro, ele sugere que, por erro de copista, duas palavras do texto original de Jó 26,13a foram convertidas em uma só palavra - שם e foram unidas e produziu-se, assim, a atual forma שמים do texto massorético e da BHA - que ainda desconhece o fenômeno.

Vamos, pois, aos fatos e aos argumentos. 


\section{0 texto de Jó 26,12-13 na BHS}

O texto de Jó 26,12-13, proposto pela BHS ${ }^{1}$ é o seguinte:

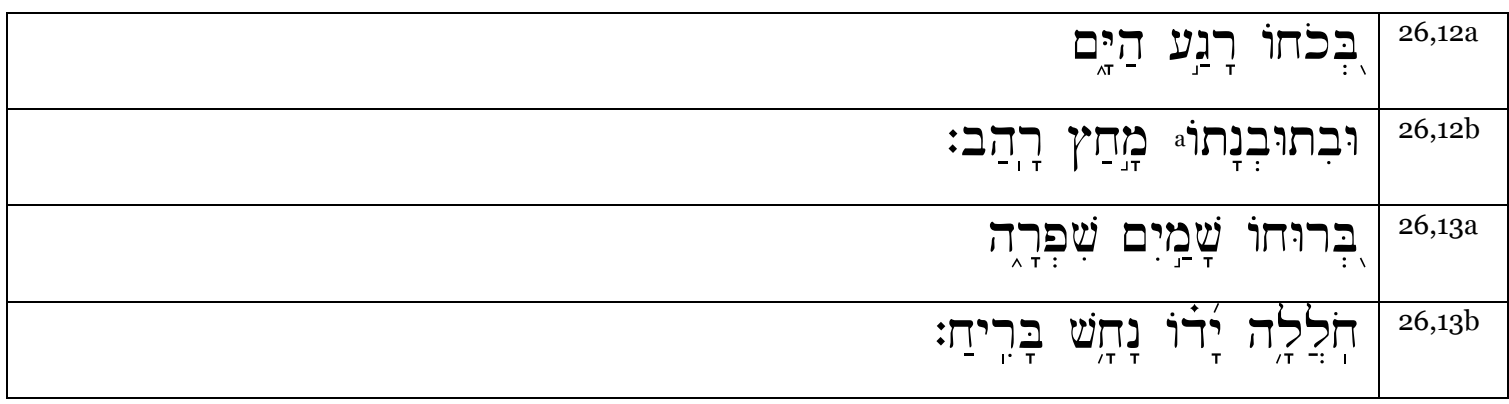

Considerando-se esses dois versos, a única observação crítica que consta do

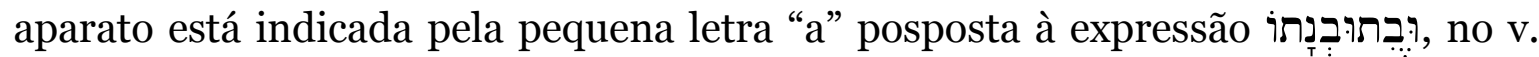
12b. No aparato, a nota "a" remete à observação de que o que está escrito constitui "error scriptoris", sugerindo-se, como correção do que está escrito, a leitura

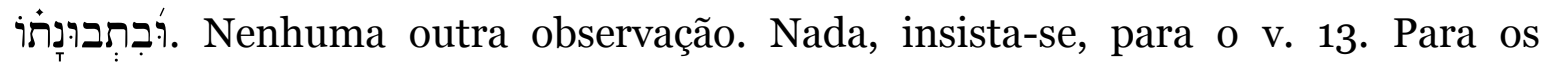
editores da BHS, além do indicado, o texto não revela outro problema, nem mesmo o fato de que, como se verá, no texto como proposto, o terceiro verso (v. 13a) rompa a série de referências ao(s) monstro(s) cosmogônico(s) dos v. 12a, 12b e 13b - Yam, Rahab e a "serpente 'fugidia" (ou "serpente primitiva" [DAY, 1998, p. 430431]), respectivamente. No v. 13a, nenhuma referência a ele(s)... E, se a BHS não vê problemas em Jó 26,13, a fortiori não o vêem as versões. Nenhuma versão consultada conhece a proposta de Cohen, ou, se a conheceu, não a levou a termo².

\footnotetext{
${ }^{1} \mathrm{O}$ texto hebraico utilizado neste artigo é RÜGER, H. P. Biblia Hebraica Sttutgartensia. Editio quarta emendata. Stuttgart: Deutsche Bibelgeselschaft, 1990, em: Biblia Sacra utriusque testamenti editio hebraica et graeca. Stuttgart: Deutesche Bibelgesellschaft, 1994.

${ }^{2}$ Pareceu ao pesquisador que a indicação, no corpo do artigo, de cada uma das versões consultadas resultaria inútil. Nenhuma delas conhece ou acata a proposta de Cohen - e todas assumem o vocábulo ymv como constante da BHS. Na hipótese de ter-se encontrado - e não foi o caso - apenas uma versão que houvesse reformulado Jó 26,13 nos termos aqui discutidos justificaria a citação dessa versão. Registre-se apenas que foram consultadas versões no vernáculo, em inglês, em italiano, em espanhol, em francês e em alemão.
} 


\section{Um problema de crítica textual da Bíblia Hebraica - erros de união ou divisão de palavras}

Voluntárias ou involuntárias, a transmissão da Bíblia Hebraica não se deu sem corrupções textuais (WÜRTHWEIN, 1994, p. 107-112), restando aos especialistas o desenvolvimento de métodos para a sua identificação e correção (WÜRTHWEIN, 1994, p. 113-120).

De interesse específico para o presente artigo, é o erro caracterizado pela ligação ou separação de palavras, o que consiste em, inadvertidamente, o copista ligar duas palavras originalmente separadas ou separar em duas partes, logo, duas palavras independentes, uma originalmente única palavra do texto. "Este tipo de erro (...) era muito freqüente na escritura consonântica contínua ["scriptio continua" (WÜRTHWEIN, 1994, p. 110)], que não deixava espaço entre as palavras. Era fácil separar erradamente as consoantes, dividindo uma palavra em duas ou fazendo de duas palavras uma só” (BARRERA, 1995, p. 444).

Os erros por separação ou união incorreta de palavras são, por exemplo, apontados por Würthwein (WÜRTHWEIN, 1994, p. 110), Fiorenza (SCHUESSLER-FIORENZA, 1978, p. 499), Mainville (MAINVILLE, 1999, p. 44) e Pisano (PISANO, 2000, p. 68) e podem ser identificados em passagens (Sl 73,1; Is 2,20; Jr 2,21 e Am 6,12) citadas pelos autores acima.

Tais erros dificultam a compreensão de um texto, mas, felizmente, eles podem ser identificados por meio do contexto, como no caso de Amós 6,12b: “a tradução 'arar com vacas' (Alonso-Schökel) corresponde à palavra hebraica bbqrym (TM), enquanto que 'arar com bois o mar' (Cantera-Iglesias) traduz duas palavras hebraicas bbqr ym (BHS). O contexto fala de coisas impossíveis ou difíceis, como é o $\operatorname{arar}$ o mar [no v. b] ou trotear sobre as rochas [no v. a]" (BARRERA, 1995, p. 445). 
Conforme se verá, Cohen sugere que, em Jó 26,13, tenha ocorrido exatamente um erro desse tipo: por conseqüência de um lapso de copista, o que seriam originalmente duas palavras resultou, por aglutinação, em uma única palavra, com sentido, naturalmente, totalmente distinto - sãs palavras hebraicas שם e שמים do foram unidas e transformadas na atual forma do texto massorético e da BHS. Esse, todavia, não é o único problema de Jó 26,13a.

\section{Um caso de hapax legomenon na Bíblia Hebraica}

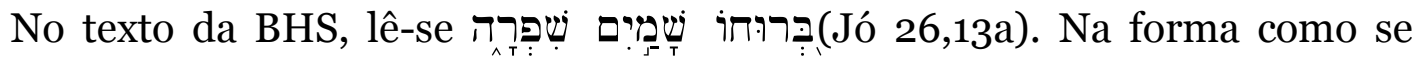

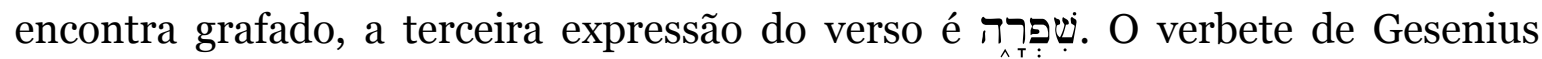
para שִשֶפר foi o mais elaborado dentre os consultados. Especificamente, para a tradução, apresenta duas opções, "brightness, beauty", e, acatando a sugestão de Simonis, aceita a sua aplicação nesse sentido para Jó 26,13: "by his (God's) Spirit the heaven are brightness, i. e, are bright, splendid, beautiful". Gesenius observa, todavia, que a maioria dos intérpretes (sic - "most intpp") tomavam a forma como

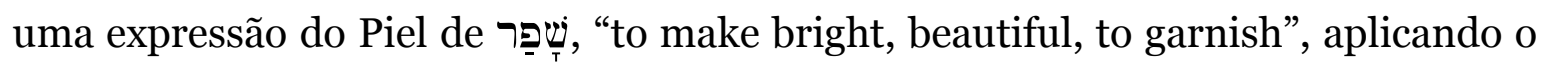
seu sentido às estrelas e constelações que ornamentavam os céus, como faz a Vulgata: "spiritus ejus ornavit caelos", o que, todavia, se rejeita por questões fonético-gramaticais (GESENIUS, 1844, p. 1095). O próprio Simonis, por sua vez, traduzia "spiritu suo coelos serenat (pr. decorat)" ("seu espírito limpou/embelezou os céus" - SIMONIS 1828, 1018).

Com efeito, mantendo a tradição dos séculos XVIII e XIX, a bibliografia consultada divide-se em dois grupos - aqueles que optam por tratar a palavra como substantivo e aqueles que optam por tratá-la como verbo.

Como verbo, o Dicionário Hebraico-Português de Kirst, Kilpp, Schwantes, Raymann e Zimmer dá o sentido de "polir" para o que seria, então, a forma I da

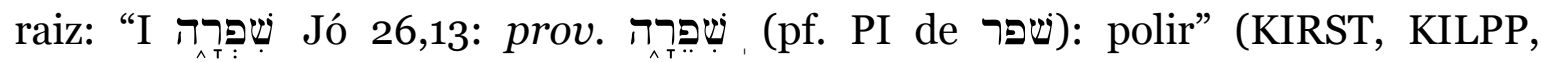


SCHWANTES; RAYMANN e ZIMMER, 2007, p. 260). Parece-me que não seja difícil inferir que o fato de a palavra anterior a esta estar grafada como "céus" induziu à opção pelo homônimo verbo hebraico שפר, já que o sentido da raiz precisa encontrar-se em harmonia com o sentido da agora palavra aglutinada fato, é verdade, que nem os tradutores nem os dicionaristas levam em consideração. Também tratando a palavra como verbo, extremamente conciso é o verbete no dicionário organizado por Fohrer: "I שִׁפְּר being clear" (FOHRER, 1973, p. 293).

Por outro lado, as demais fontes consultadas tratam שִׁפִרֶה como

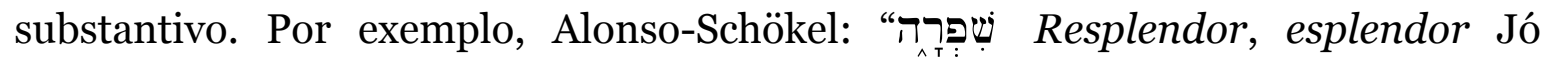
26,13" (ALONSO-SCHÖKEL, 1997, p. 690). Isso, todavia, em seu dicionário. Que se está, contudo, diante de uma dificuldade, revela-o tanto a tradução brasileira de Jó 26,13a na Bíblia do Peregrino, "ao seu sopro o céu resplandece”, quanto em sua versão original, Biblia del Peregrino, "a su soplo el cielo resplandece", bem como eu seu comentário a Jó, que segue a mesma tradução da Biblia del Peregrino (ALONS-SCHÖKEL; DÍAZ, 2002, p. 499): o que é dado como substantivo no dicionário, aparece como verbo, nas duas versões e no comentário.

Classificando שִׁפְרָרה como um hapax legomenon, Klein, um judeu, traduz o vocábulo como o substantivo feminino "beauty (a hapax legomenon in the Bible occurring Job 26:23 (sic) [Prob. formed from שפר (...)])" (KLEIN, 1987, p. 676). "Beauty" é também a tradução proposta por HALOT, que indica a ocorrência de Jó 26,13, traduzindo a passagem como "the heavens became bare with his wind" (KOEHLER; BAUMGARTNER; STAMM, 2000). Já Brow, Drives e Biggs traduzem o vocábulo como substantivo feminino: "fairness, clearness, of sky (...) Jb 26:13 by his breath the sky becomes fair(ness)" (BROWN; DRIVES; BRIGGS, 1951, p. 2555). 
Como se verá adiante, segundo Cohen, o primeiro especialista a identificar em שִשְפרָה não um termo propriamente hebraico, mas um cognato etimologicamente derivado do acádico "saparru", foi Tur-Sinai, em 19413. Como se pode observar, até onde se pode acompanhar, a identificação de Tur-Sinai e a recomendação de Harold Cohen (1975/1978) não foram suficientes para a correção do texto hebraico padrão da BHS nem para alterar os dicionários e léxicos da área - e, por conseguinte, as versões.

\section{A proposta de Harold R. Cohen de correção do texto massorético de Jó 26,13}

No quadro abaixo, pode-se analisar a proposta de correção do texto hebraico da BHS apresentada por Cohen.

Proposta de correção de Harold R. Cohen

By his wind, he put Yam into his net

His hand slew the serpent slant

\begin{tabular}{|c|c|c|c|c|c|c|}
\hline בריח & נחש & ידו & חללה & שפרה & שם ים & ברוחו \\
\hline 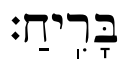 & נָחָש & דידוֹ & חָלְלְלִה & שִׁפְּרה & 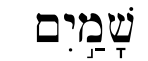 & בְּרוּחוֹו \\
\hline
\end{tabular}

Biblia Hebraica Stuttgartensia

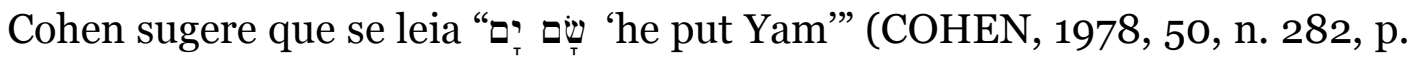
97) em lugar de שִמנמיזים ("céus"), como consta do texto massorético e da BHS. A hipótese em jogo é de que algum copista tenha, inadvertidamente, unido, sem que

\footnotetext{
${ }^{3}$ Consta publicação, vinte anos antes, do comentário alemão de Tur-Sinai, ao qual, todavia, não se teve acesso para poder-se verificar se já então, se fazia referência à alegada derivação etimológica (cf. TUR-SINAI. Das Buch Hiob. Eine Kritische Analyse des Überlieferten Hiobtextes. Wien/Berlin: R. Löwit, 1920).
} 
o devesse, a segunda e a terceira palavras do então original texto hebraico (ש e י), entendendo que se devesse ler a palavra שמים ("céus”). Provavelmente o escriba tivesse perdido acesso ao sentido original da então quarta palavra do texto (שפרה), interpretando-a agora não mais a partir do sentido com que o escritor a teria empregado - acádico, na hipótese de Cohen -, mas atualizando-a por meio de um dos sentidos de raiz homônima disponíveis em sua própria cultura.

\section{A proposta de Harold R. Cohen para o sentido de שפרה em Jó 26,13}

O copista responsável pela aglutinação das duas palavras em uma parece não ter captado o sentido acádico da raiz שפרה que tinha diante de si. O argumento de Cohen quanto à derivação etimológica do acádico se baseia em uma linha do épico babilônico, Enūma eliš , que ele apresenta transliterado e traduzido:

ušParrirma Bëlum saParrašu ušalmëši ${ }^{4}$

The Lord (Marduk) spread out his net and enmeshed her (Tiamat) 5

O deus cosmogônico guerreiro lança a sua rede e prende o dragão cosmogônico. O termo hebraico cujo sentido eventualmente o escriba teria perdido - שפרה - seria o correlato do termo acádico "saparru" (COHEN, 1978, p. 50; SALONEN, 1965, p. 97), equivalente ao termo sumeriano SA.PAR (COHEN, 1978, 50, n. 288, p. 98). Com efeito, o léxico sumeriano de Halloran traz: "sa-par 4 ; sipar $_{4}$ : a type of net ('net'/'to fill' + 'to stretch out')" (HALLORAN, 1999, p. 133).

\footnotetext{
${ }^{4}$ O verso é indicado como Enūma eliš IV:95 (COHEN, 1978, p. 50). Em nota, Cohen ainda remete para IV:41.44; V:64 e VI:83, além de recomendar que se note a expressão "saparriš 'in the net'" em IV:112. Com base em, as referências seriam: para IV:41, "he made a net to inclose Tiamat within (it)" (HEIDEL, 1951, p. 38); para VI:83, "the net which he had made (...)" (p. 49); e, para IV:112, "in the net they lay and in the snare they were" (p. 41).

${ }^{5}$ A mesma tradução encontra-se em HEIDEL, 1951, p. 41. "O Senhor (Marduk) lançou sua rede e a (Tiamat) capturou", em tradução livre do pesquisador.
} 
Cohen afirma que o primeiro a ter comparado o acádico "saparru" com o termo hebraico de Jó 26,13 teria sido Tur-Sinai, em seu comentário a Jó, em Hebraico, de 1941 (TUR-SINAI, 1941, p. 314; TUR-SINAI, 1957, p. 383)6. A afirmação de Tur-Sinai foi reconhecida e acatada por Pope em seu comentário de 1973 (POPE, 1973, p. 166; WAKEMAN, 1973, p. 57-58, nota 2). Desconhecem-se outras recepções explicitadas - salvo, naturalmente, Cohen7.

Para o contexto, Cohen argumenta o seguinte (COHEN, 1978, 50 e notas): tanto no Enūma eliš quanto em Jó 26,12-13, trata-se da batalha do deus contra $\mathrm{o}(\mathrm{s})$ monstro(s) marinho(s). Nos dois casos, (parece ser correto afirmar que) a estratégia do deus é empregar a rede e o vento contra o adversário de batalha, ainda que no Enūma elǐs [IV:93-103] (HEIDEL, 1951, p. 40), Marduk empregue, além da rede (IV:95) e do vento (IV:96.98-99), também a flecha ("arrow" IV:101) ${ }^{8}$. O deus lança a sua "tarrafa" sobre ela (IV:95) e, quando Tiamat abre a boca para tentar engoli-lo (IV:97), Marduk usa o "vento mal" ("evil wind") para inflar seu corpo e manter a boca do dragão aberta (IV:98-100), para, então, com um tiro certeiro, ferir-lhe, por aí, com a flecha, cortando e ferindo o coração de Tiamat (IV:100-103). Enquanto, em Jó, se menciona o ataque de Yahweh com seu vento, sua rede e sua mão, no Enūma eliš, Marduk ataca com o “'vento' mal”, sua rede e uma flecha. Com a flecha, Marduk corta Tiamat por dentro, chegando até seu coração - com sua mão, Yahweh "transpassa" (9חל) a "serpente 'fugidia' (ou 'primeva', ou 'tortuosa')". É evidente a correlação contextual. A despeito da semelhança inegável entre a expressão "serpente "fugidia", de Jó 26,13, e a expressão (traduzida por de Moor) "fleeing serpent" do hino Baal V (KTU 1.5) (DE

\footnotetext{
${ }^{6}$ A obra indicada por Cohen é TUR-SINAI, N. H. bwya rps II. Jerusalem, 1941, p. 341, de que TUR-SINAI, 1957 é a tradução em inglês, a que apenas o pesquisador teve acesso.

${ }^{7}$ Não estou em condições de afirmar que esgotei as consultas possíveis. Algum pesquisador com melhor acesso à literatura internacional talvez pudesse certificar-se quanto ao fato de se o resultado de minha pesquisa, no conjunto da literatura que consultei, se confirmaria no conjunto da literatura internacional.

${ }^{8}$ Trata-se, todavia, de uma questão que precisa ser aprofundada. É possível tratar-se xwr como uma arma física, o arco. Nesse sentido, talvez se pudesse, também em Jó 26,13, tratar xwr como o correlato do arco dos deuses mesopotâmicos que enfrentam o dragão (WARD, 1898, p. 94-105) e interpretar-se esse xwr como o próprio arco de Yahweh - quanto a isso, cf. LOEWENSTAMM, 1992, p. 111 e, além desse, também para o tema de xwr como ira de Yahweh, cf. COHEN, 1975, p. 17, nota 28. Não é, todavia, tema que aqui se possa enfrentar.

${ }^{9}$ Ilx - "transpassar, atravessar, furar, perfurar; apunhalar, esfaquear, malferir" (ALONSO-SCHÖKEL, 1997, p. 224).
} 
MOOR, 1987, 65 e n. 324) ${ }^{10}$, é de todo arriscado assumir-se que se tem, aí, "uma conexão (...) distante com a epopéia babilônica da criação” (ANDERSEN, 1996, p. 216) - desde o século XIX se conhece a relação, inclusive imagética, entre os temas cosmogônicos bíblicos (incluindo Jó) e os mitos e a iconografia do Antigo Oriente Próximo, largamente influente, aí, a ampla região mesopotâmica (WARD, 1898, p. 94-10511). Uma herança "palestinense" pré-exílica não impediria a recepção de tradições cosmogônicas e motivos similares - e, mesmo, vocabulário! mesopotamicamente atualizados pelas gerações pós-exílicas, quanto mais aquelas diretamente afetadas pela transferência física para a Babilônica justamente da intelligentsia judaíta...

No campo internamente intertextual, todavia, a balança pesa sensivelmente a favor de uma "dependência” das tradições mesopotâmicas. Cohen não emprega o argumento, mas talvez se poderia recorrer a ele: Jó 7,12 e 9,13 podem ser assumidos como referências a pelo menos uma versão mesopotâmica da batalha do deus contra o dragão - o que reforçaria a tese de que o termo שפרה tenha sido usado em Jó 26,13 a partir do sentido do termo acádico saparru, atestado no Enūma eliš.

Jó 7,12 pode ser traduzido como "o Mar sou eu, ou o dragão, para que

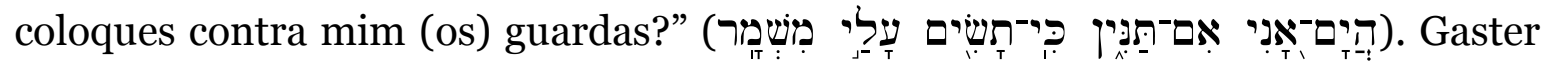
afirma que Jó 7,12 depende de Enūma eliš IV:139: "he fixed the crossbar (and) posted guards" (GASTER, 1961, p. 145; HEIDEL, 1951, p. 42). De igual modo, Gaster afirma que o texto de Jó 9,13 se refere diretamente a Enūma eliš V:107-108. Aqui, afirma-se que os deuses ajudadores de Tiamat marcharam ao lado dela, mas que, à visão de Marduk, eles “quivered, feared, turned tail” (GASTER, 1961, p. 146; HEIDEL, 1951, p. 41). Lá, Jó afirma que, debaixo do deus, “prostram-se os

\footnotetext{
${ }^{10}$ Com efeito, a semelhança entre Jó 26,13 e KTU 1.5 é inegável: “(...) you defeated Lotanu, the fleeing serpent, / destroyed the coiling serpent, / the Tyrant with the seven heads (...)" (DE MOOR, 1987, p. 65; cf. BARRERA, 1995, p. 254).

${ }^{11}$ A despeito de "antigo", o texto de Ward é realmente útil, dado o conjunto de imagens representando a batalha entre o deus e o dragão cosmogônico em diversas tradições próximo-orientais, especialmente as mesopotâmicas, com paralelos em Jó também tratados.
} 


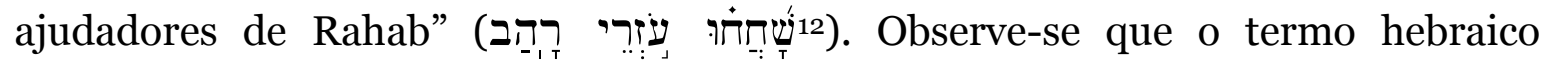
empregado em Jó 9,13 é o mesmo termo hebraico empregado em Jó 26,13 - רַהב ("Rahab"): o dragão babilônico tinha seus "ajudadores" - Jó refere-se aos "ajudadores de Rahab" (9,13), Rahab que, em 26,12 é retratada igualmente como o dragão cosmogônico, de modo que "os ajudadores de Rahab" são correlatos dos "ajudadores de Tiamat". Dificilmente se pode fugir ao assentimento de que, assim como Jó 7,12 e 9,13 dependem intertextualmente de Enūma eliš, da mesma forma os versos de Jó 26,12-13 emprestam do termo acádico do épico babilônico a arma de Yahweh - a rede (שפרה/saparru), com que captura o dragão cosmogônico. Se Jó 7,12 e 9,23 são casos de intertextualidade entre Jó e o Enūma eliš, não se vê razão para que Jó 26,12-13 não possa, igualmente, ser... E, nesse caso, argumentase em favor da identificação de Tur-Sinai (1941) e de Cohen (1975 [1978]) quanto à derivação etimológica do hebraico שפרה acádico "saparru".

Se, por um lado, a comparação de Jó 26,13 com o épico babilônico revela equivalência da ação e dos instrumentos bélicos com que o deus cosmogônico enfrenta o dragão, e, ainda nesse sentido, o verso se alia a Jó 7,12 e Jó 9,13 na referência ao épico babilônico - revelando, assim, a procedência teóricometodológica da proposta de Cohen, por outro lado, internamente, o conjunto do versos de Jó 26,12-13 revela-se perfeitamente sinonímico, se acatada a - já a essa altura, formidável - proposta de correção do texto massorético.

Como se disse acima, na forma como se encontra impresso o texto hebraico da BHS, o v. 13a revela-se fora do padrão sinonímico que se esperaria, uma vez que, de um lado, os estíquios do v. 12 estão em paralelismo sinonímico, enquanto os do v. 13, não. A proposta de Cohen corrige essa quebra de estrutura sinonímica,

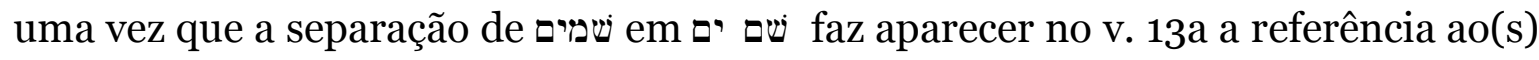
monstro(s) cosmogônico(s) que aparece(m) em todos os outros estíquios dos v. 12 e 13.

\footnotetext{
${ }^{12}$ O próprio Gaster traduz “helpers of Rahab” (GASTER, 1961, p. 147).
} 
Nesse caso, estaríamos diante de uma série de quatro estíquios em paralelismo sinonímico. Se observarmos que o conteúdo é explicitamente cosmogônico, talvez se pudesse recordar de um caso que, se não me equivoco, é formal e materialmente equivalente a Jó 26,12-13 - Pr 30,4. Em Pr 30,4, há também quatro estíquios, em paralelismo e em contexto cosmogônico: "30,4a Quem subiu os céus e desceu? / 4b Quem aprisionou o vento com seus punhos? / 4c Quem encerrou as águas no manto? / 4d Quem levantou todo o confim da terra?” (RIBEIRO, 2005, p. 1379). Não se trata de paralelismo sinonímico, a despeito do conteúdo gravitar em torno da cosmogonia, bem como não se faz referência ao dragão ${ }^{13}$ - mas o fato de se tratar de quatro declarações (assertivas, em Jó, retóricas, em Provérbios) em paralelo parece permitir uma aproximação heurística entre as duas passagens. Uma ao lado da outra, essas quatro declarações/questões, tanto em Jó 26,12-13 quanto em Pr 30,4, parecem constituir evidências daqueles enigmas e daquelas disputas cosmogônicas descritas por Huizinga (HUIZINGA, 2005, p. 128) em Homo Ludens, o que talvez indicaria mesmo um tipo de gênero retórico não incomum. E, nesse caso, a recordação de que o "Jó babilônico" igualmente contém "questões" cosmogônicas (TERRIEN, 1994, p. 208, nota 19) deveria ser acessado como argumento heurístico para a proposta de Cohen.

A despeito da - aqui assumida - validade da proposta de Cohen, ela permanece desconhecida ou negligenciada por renomados comentaristas, tais como: a) Day (DAY, 1998, p. 430: "by His Spirit [or Wind, רוח] the heavens became fair"), que, a despeito de citar Pope, que acata a sugestão de Tur-Sinai, mantém a leitura tradicional de Jó 26,13a; Witte (WITTE, 1994, p. 144-154), que, a despeito da profunda referenciação bibliográfica do volume e, além disso, de também ter tido acesso a Pope, chega a utilizar-se de "Himmel" (“céus"), de Jó 26,13, como elemento estrutural da composição do capítulo (- mas, se Cohen está

\footnotetext{
${ }^{13}$ Reconhece-se uma tendência ao abrandamento e, mesmo, ao desaparecimento do tema do dragão ou dos dragões cosmogônicos na literatura veterotestamentária (MAY, 1955, p. 9-21). Nesse sentido, a tradução de x:yrl)B' vx'în" em Jó 26,13b por "drakonta apostathn ('the apostate dragon')" (PHILLIPS, 2000, p. 243) é sugestiva.
} 
correto, שִשָמִים ["Himmel”, “céus”] jamais fez sequer parte do estíquio!).

Penso que passou da hora de essa dívida ser paga...

\section{Conclusão}

Em 1941, Tur-Sinai teria sido o primeiro a observar, mais do que a possibilidade, a necessidade de ler-se a palavra שפרה em Jó 26,13 a partir do cognato acádico "saparru", que significa "rede". Em 1975, Cohen recupera a observação de Tur-Sinai e a aperfeiçoa, sugerindo que, além de ter ocorrido a perda do sentido de שפרה, e talvez também por isso, um escriba cometeu um erro de copista, unindo as duas palavras que apareciam antes de שפרה, tornando-as, agora, uma única palavra. Esses dois equívocos históricos redundaram na completa perda de sentido de Jó 26,13a.

Ao lado, naturalmente, da recuperação do sentido do termo acádico “saparru” para שפרה, Cohen propõe que se corrija a aglutinação das palavras $ם$ שם ים שפרה - שמים emestaurando a leitura original do texto hebraico, rem ברוחו. Desde a defesa de sua dissertação, em 1975, e a publicação dela em forma de livro, em 1978, todavia, a proposta encontra-se negligenciada.

Se Cohen for atendido em sua proposta, poder-se-ia ler, no vernáculo, a fórmula cosmogônica de quatro estíquios de Jó 26,12-13 mais ou menos assim: "com sua força, sacudiu Yam, / com sua destreza, malferiu Rahab. / Com seu vento, prendeu Yam na sua rede, / transpassou a sua mão a serpente primitiva”. 


\section{REFERÊNCIAS}

ALONSO-SCHÖKEL, L. Biblia del Peregrino. Antiguo Testamento. Poesía. Edición de Estudio. Tomo II. Bilbao: Ega, Mensajero e Navarre: Verbo Divino, 2009.

ALONSO-SCHÖKEL, L. Bíblia do Peregrino. São Paulo: Loyola, 2002.

ALONSO-SCHÖKEL, L. Dicionário Hebraico-Português. São Paulo: Paulus, 1997.

ALONSO-SCHÖKEL, L. e SICRE-DÍAZ, J. L. Job - comentario teológico y literario.

Madrid: Cristiandad, 2002.

ANDERSEN, F. I. Jó - introdução e comentário. São Paulo: Vida Nova, 1996.

BARRERA, J. T. A Bíblia judaica e a Bíblia cristã: introdução à história da Bíblia. Petrópolis, Vozes, 1995.

BARRERA. J. T. El relato de Jezabel (2 Re 9, 30-37). Lectura fenomenológica de un texto bíblico. 'Illu - Revista de Ciencias de las Religiones, n. o, 1995, p. 249-251.

BROWN, F.; DRIVER, S. R. e BRIGGS, C. A. The Enhanced Brown-Driver-Briggs Hebrew and English Lexicon. Oxford: Oxford Universty Press, 1951.

COHEN, H. R. (Chaim). Biblical hapax legomena in the Light of Akkadian and Ugarit. Missoula: Scholar Press, 1978.

COHEN, H. R. (Chaim). Studies in early Israelite poetry I: an unrecognized case of threeline staircase parallelism in the Song of the Sea. Journal of Ancient Near West Studies, 7, 1975 .

DAY, J. God and Leviathan in Isaiah 27:1. Bibliotheca Sacra, n. 155, 1998, p. 423-436.

DE MOOR, J. C. An Anthology of Religious Texts from Ugarit. Leiden: Brill, 1987.

FOHRER, G. (ed). Hebrew and Aramaic Dictionary of the Old Testament.

Berlin/New York: Walter de Gruyter,1973.

GASTER, T. H. Thespis. Ritual, myth and drama in Ancient Near East. New York: The Norton Library, 1961.

GESENIUS, W. A Hebrew and English Lexicon of the Old Testament: including the Biblical Chaldee. Boston: Crocker and Brewster, 1844.

HEIDEL, A. The Babylonian Genesis. The Story of Creation. 2 ed. Chicago/London: University of Chicago, 1951. 
HALLORAN, J. A. Sumerian Lexicon. Version. 3.o. 1999. Disponível em: <http://www.sumerian.org/sumerian.pdf>. Acesso em: o6 maio 2015.

HUIZINGA, J. Homo Ludens. São Paulo: Perspectiva, $2005^{5}$.

KIRST, N.; KILPP, N.; SCHWANTES, M.; RAYMANN, A. e ZIMMER, R. Dicionário Hebraico-Português e Aramaico-Português. São Leopoldo: Sinodal, Petrópolis: Vozes, 2007.

KLEIN, E. A Comprehensive Etymological Dictionary of the Hebrew Language for Readers of English. Jerusalem: Carta, Haifa: The University of Haifa, 1987.

KOEHLER, L.; BAUMGARTNER, W. e STAMM, J. J. Hebrew and Aramaic Lexicon of the Old Testament. Leiden: Brill, 2000.

LOEWENSTAMM, S. E. The evolution of the Exodus tradition. Jerusalem: Magnes Press, 1992.

MAINVILLE, O. A Bíblia à luz da história: guia de exegese histórico-crítica. São Paulo: Paulinas, 1999.

MAY, H. G. Some cosmic connotations of Mayim Rabbîm, 'Many Waters', Journal of Biblical Literature, v. 74, n. 1, 1955, p. 9-21.

PHILLIPS, E. A. Serpent Intertexts: Tantalizing Twists in the Tales. Bulletin for Biblical Research, v. 10, n. 2, 2000, p. 233-245.

PISANO, Stephen. "O texto do Antigo Testamento", em: SIMIAN-YOFRE, H.; GARGANO, I.; SKA, J. L. e PISANO, S. Metodologia do Antigo Testamento. São Paulo: Loyola, 2.000, p. 39-72.

POPE, M. H. Job: Introduction, translation, and notes. New York, Doubleday, 1973.

RIBEIRO, O. L. Como que pelos chifres: o vento na criação, segundo Pr 30,4.

Fragmentos de Cultura, v. 15, n. 9, 2005, p. 1371-1383.

RÜGER, H. P. Biblia Hebraica Sttutgartensia. Editio quarta emendata. Stuttgart: Deutsche Bibelgesellschaft, 1990, em: Biblia Sacra utriusque Testamenti editio hebraica et graeca. Stuttghart: Deutesche Bibelgesellschaft, 1994.

SALONEN, E. Die Waffen der alten Mesopotamier: eine lexikalische und kulturgeschichtliche Untersuchung. Helsinki: Societas Orientalis Fennica, 1965.

SCHUESSLER-FIORENZA, E. "Exemplificação do método exegético", em: SCHREINER, J. Palavra e Mensagem. Introdução teológica e crítica aos problemas do AT. 2 ed. São Paulo: Paulinas, 1978, p. 497-526. 
SIMONIS, J. Lexicon Manuale Hebraicum et Chaldaicum in Veteris Testamenti Libros. 4 ed. Lipsiae: Fredericum Fleischer, 1828.

TUR-SINAI. Das Buch Hiob. Eine Kritische Analyse des Überlieferten Hiobtextes. Wien/Berlin: R. Löwit, 1920.

TUR-SINAI, N. H. The Book of Job. A New Commentary. Jerusalém: Kiryath Sepher, 1957.

TERRIEN, S. Jó. São Paulo: Paulus, 1994.

WAKEMAN, M. K. God's battle with the monster. A study in biblical imagery. Leiden: Brill, 1973 .

WARD, W. H. Bel and the Dragon. The American Journal of Semitic Languages and Literatures, v. 14, n. 2, 1898, p. 94-105.

WITTE, M. Vom Leiden zur Lehre: Der dritte Redegang (Hiob 21-27) und Die Redaktionsgeschichte Des Hiobbuches. Berlin : Walter de Gruyter, 1994.

WÜRTHWEIN, E. An introduction to the Biblia Hebraica. 2 ed. Revised and enlarged. Grand Rapids: Eerdmans, 1994. 